\title{
HIF2a regulates the synthesis and release of epinephrine in the adrenal medulla
}

\author{
Deepika Watts ${ }^{1} \cdot$ Nicole Bechmann ${ }^{1,2,3} \cdot$ Ana Meneses $^{1} \cdot$ Ioanna K. Poutakidou $^{1} \cdot$ Denise Kaden $^{1} \cdot$ Catleen Conrad $^{1}$. \\ Anja Krüger ${ }^{1}$. Johanna Stein ${ }^{1}$ - Ali El-Armouche ${ }^{4} \cdot$ Triantafyllos Chavakis $^{1}$. Graeme Eisenhofer ${ }^{1,5}$. Mirko Peitzsch ${ }^{1}$. \\ Ben Wielockx ${ }^{1}$ (i)
}

Received: 5 February 2021 / Revised: 16 July 2021 / Accepted: 20 July 2021 / Published online: 4 September 2021

(c) The Author(s) 2021

\begin{abstract}
The adrenal gland and its hormones regulate numerous fundamental biological processes; however, the impact of hypoxia signaling on adrenal function remains poorly understood. Here, we reveal that deficiency of HIF (hypoxia inducible factors) prolyl hydroxylase domain protein-2 (PHD2) in the adrenal medulla of mice results in HIF2 $\alpha$ mediated reduction in phenylethanolamine $\mathrm{N}$-methyltransferase (PNMT) expression, and consequent reduction in epinephrine synthesis. Simultaneous loss of PHD2 in renal erythropoietin (EPO)-producing cells (REPCs) stimulated HIF2 $\alpha$-driven EPO overproduction, excessive RBC formation (erythrocytosis), and systemic hypoglycemia, which is necessary and sufficient to enhance exocytosis of epinephrine from the adrenal medulla. Based on these results, we propose that the PHD2-HIF2 $\alpha$ axis in the adrenal medulla regulates the synthesis of epinephrine, whereas in REPCs, it indirectly induces the release of this hormone. Our findings are also highly relevant to the testing of small molecule PHD inhibitors in phase III clinical trials for patients with renal anemia.
\end{abstract}

Ben Wielockx

Ben.Wielockx@tu-dresden.de

1 Institute of Clinical Chemistry and Laboratory Medicine, Technische Universität Dresden, Fetscherstrasse 74, 01307 Dresden, Germany

2 Department of Experimental Diabetology, German Institute of Human Nutrition Potsdam-Rehbruecke, 14558 Nuthetal, Germany

3 German Center for Diabetes Research (DZD), 85764 München-Neuherberg, Germany

4 Department of Pharmacology and Toxicology, Medical Faculty, Technische Universität Dresden, 01307 Dresden, Germany

5 Department of Medicine III, Medical Faculty, Technische Universität Dresden, 01307 Dresden, Germany

\section{Key messages}

- HIF2 $\alpha$ and not HIF $1 \alpha$ modulates PNMT during epinephrine synthesis in chromaffin cells.

- The PHD2-HIF2 $\alpha$-EPO axis induces erythrocytosis and hypoglycemia.

- Reduced systemic glucose facilitates exocytosis of epinephrine from adrenal gland.

Keywords Hypoxia inducible factor - Catecholamines . Oxygen sensors · Glucose

\section{Introduction}

The hypoxia signaling pathway regulates expression of myriad genes involved in various biological processes in living animals; the hypoxia inducible factors (mainly HIF1 and HIF2) are the central transcription factors that regulate these processes. HIF expression, in turn, is under the direct control of a set of oxygen sensors known as the HIF-prolyl hydroxylase domain-containing proteins (PHD1-3). Under normoxic conditions, PHDs use oxygen as a co-factor to hydroxylate two prolyl residues in the HIF $\alpha$ subunits, thereby making HIFs accessible to the von Hippel-Lindau protein complex (pVHL) for subsequent ubiquitination and degradation [1]. Reduced cellular oxygen levels preclude such hydroxylation of HIFs by PHDs, resulting in stabilization of HIF $\alpha$ and direct transcriptional activation of more than 1000 genes. HIF transcriptional targets are primarily involved in a wide range of biological processes that serve to reverse the unfavorable hypoxic state, including erythropoiesis, blood pressure regulation, and adrenocortical hormone production [2-4]. Hypoxia is also a central feature of multiple pathologies, including local and systemic inflammation, and various stages of tumorigenesis or metastatic progression; gene mutations that impact hypoxia signaling are particularly 
important for development of pheochromocytomas, tumors originating from the adrenal chromaffin cells [5].

Adrenal chromaffin cells are the principal endocrine cells of the adrenal medulla and, as the source of catecholamines, are crucially involved in the fight-or-flight response, which requires epinephrine secretion [6]. Biosynthesis of epinephrine is catalyzed by the enzyme phenylethanolamine N-methyltransferase (PNMT), which converts norepinephrine to epinephrine. Several in vitro studies have focused on HIF involvement in regulating the enzymatic activity required for catecholamine synthesis, including a role for HIF $2 \alpha$ in the expression of dopamine $\beta$-hydroxylase (DBH) and Dopa decarboxylase (DDC) in immortalized rat fetal adrenal medullary cell lines [7]. Conversely, another in vitro study found no impact of HIF $2 \alpha$ expression on tyrosine hydroxylase (TH) or Dbh [8], while downregulating PNMT expression [9]. The latter finding is in line with results from a number of other studies that have connected HIF $2 \alpha$ activity in the adrenal medulla or in pheochromocytomas with reduced PNMT production [9-11]. Tumors with pVHL mutations also overexpress HIF2 target genes such as erythropoietin (EPO), a hormone central to red blood cell (RBC) formation $[12,13]$. Despite these observations, studies focusing on how modulation of hypoxia pathway proteins affect adrenal function are sparse, and only recently has a transgenic mouse line harboring a whole body HIF $2 \alpha$ gain-of-function mutation been described, which showed reduced PNMT in the adrenal glands [14].

Circulating concentrations of epinephrine during hypoglycemia can increase up to 30-fold. Actually, hypoglycemia stimulates the adrenal medulla rather specifically compared to the neuronal components of the sympathetic nervous system [15-17]. Hyperglycemia is associated with inhibition of insulin exocytosis from $\beta$-cells $[18,19]$ but has also been suggested to inhibit the release of epinephrine [20]. Interestingly, elevated levels of systemic EPO or treatment with erythropoiesis stimulating agents are directly linked to a reduction in blood glucose levels (BGLs), possibly due to higher glucose consumption by increased numbers of RBCs [21-23]. As the production and release of epinephrine are critical, in vivo studies are essential to better understand the direct and/or indirect impact of alterations in hypoxia pathway proteins on epinephrine production and release from the adrenal gland.

Here, we performed an in-depth study of the synthesis of epinephrine and its release from the adrenal gland using several transgenic mice models that exhibit functional changes in one or more hypoxia pathway proteins. Our results demonstrate that PHD2 deficiency in the adrenal medulla, using our previously described CD68:crePHD $2^{\mathrm{f} / \mathrm{f}}$ and PHD2/HIF $1 \alpha^{\mathrm{ff} / \mathrm{ff}}$ mouse lines [24, 25], results in HIF2 $\alpha$-mediated reduction in PNMT and consequent inhibition of epinephrine synthesis in the adrenal gland. Moreover, we show that differential secretion of epinephrine from the adrenal gland is dependent on EPO/RBCinduced changes in blood glucose levels.

\section{Materials and methods}

\section{Mice}

All mouse strains were maintained under specific pathogen-free conditions at the Experimental Centre of the Medical Theoretical Center (MTZ, Technical University of Dresden-University Hospital Carl-Gustav Carus) or at the animal facility of Max Planck Institute of Molecular Cell Biology and Genetics (MPI-CBG), Dresden. Experiments were performed with both male and female mice aged between 6 and 12 weeks. No significant differences between the genders were observed. CD68:cre-PHD2/ $\mathrm{HIF} 1^{\mathrm{ff} / \mathrm{ff}}(\mathrm{P} 2 \mathrm{H} 1)$ or CD68:cre-PHD2 $2^{\mathrm{f} / \mathrm{f}}(\mathrm{P} 2)$ lines were generated in-house and have been previously described by us. Briefly, although CD68 is known as a monocyte/macrophage marker, cre-recombinase activity/targeting was found in the entire hematopoietic system (starting in the hematopoietic stem cell), a few subsets of epithelial cells, neurons, and EPO-producing cells in the kidney (REPC)

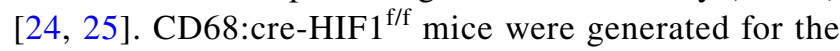
current work using the $\mathrm{HIF}^{\mathrm{f} / \mathrm{f}}$ line [26]. EPO Tg6 mice have been described earlier [27]. FOXD1:cre-HIF $2 \alpha^{\mathrm{f} / \mathrm{f}}$ mice have been described elsewhere [28] but were generated in our laboratory using the FOXD1:cre line [29] (generous gift from Dr. Todorov, Dresden, Germany) in combination with the HIF2 $^{\mathrm{f} / \mathrm{f}}$ line [30]. All mice described in this report were born in normal Mendelian ratios. Mice were genotyped using primers described in supplementary Table 1. Peripheral blood was drawn from mice by retroorbital sinus puncture using heparinized microhematocrit capillaries (VWR, Germany), and plasma separated and stored at $-80{ }^{\circ} \mathrm{C}$ until further analysis. Urine was immediately frozen on dry ice after collection and stored at $-80{ }^{\circ} \mathrm{C}$ until further analysis. Mice were sacrificed by cervical dislocation and adrenals were isolated, snap frozen in liquid nitrogen, and stored at $-80{ }^{\circ} \mathrm{C}$ for hormone analysis or gene expression analysis. All mice were bred and maintained in accordance with facility guidelines on animal welfare and with protocols approved by the Landesdirektion Sachsen, Germany.

\section{Laser microdissection}

To investigate genetic targeting of hypoxia pathway proteins in the CD68:cre line, we isolated the medullar fraction of the adrenal gland using laser microdissection. Therefore, 
adrenal glands were embedded in O.C.T Tissue-Tek (A. Hartenstein $\mathrm{GmbH}$ ) and subsequently frozen on dry ice and stored at $-80{ }^{\circ} \mathrm{C}$ until further processing. Serial sections of 25-30 $\mu \mathrm{m}$ were obtained at $-14{ }^{\circ} \mathrm{C}$ using a cryotome. The glass slides used for collection of sections were heated at $200{ }^{\circ} \mathrm{C}$ for a minimum of $3 \mathrm{~h}$ and $\mathrm{UV}$ treated for $15 \mathrm{~min}$. After collection of sections, slides were subjected to sequential dehydration in $\mathrm{H}_{2} \mathrm{O}, 75 \% \mathrm{EtOH}, 95 \% \mathrm{EtOH}$, and $100 \%$ EtOH for 1 min each and then left to dry completely. Microdissection of the adrenal medulla was performed using a PALM MicroBeam LCM (ZEISS). Tubes containing the tissue were frozen to $-20{ }^{\circ} \mathrm{C}$ until further processing and genomic DNA was isolated from the dissected tissue using the alkaline lysis buffer followed by the neutralization buffer and used as template for genomic PCR.

\section{Hormone measurement}

Adrenal glands were incubated in disruption buffer (component of Invitrogen ${ }^{\mathrm{TM}}$ Paris $^{\mathrm{TM}}$ Kit, AM 1921, Thermo Fisher Scientific) for $15 \mathrm{~min}$ at $4{ }^{\circ} \mathrm{C}$, homogenized in a tissue grinder, followed by incubation for $15 \mathrm{~min}$ on ice and further preparation [31]. Adrenal catecholamines, norepinephrine, epinephrine, and dopamine were measured by high pressure liquid chromatography (HPLC) coupled with electrochemical detection after batch extraction with alumina, as previously described [32]. Urinary catecholamines were determined by liquid chromatography tandem mass spectrometry (LC-MS/MS) as described previously [33]. All urine samples were normalized for their volume by urinary creatinine measurement.

\section{PNMT enzyme activity}

PNMT enzyme activity was analyzed by LC-MS/MS [34].

\section{RNA extraction and qPCRs}

RNA from the adrenal glands was isolated using the RNA Easy Plus micro kit (Qiagen). cDNA synthesis was performed using the iScript cDNA Synthesis Kit (BIO-RAD). Gene expression levels were determined by quantitative realtime PCR using the "Ssofast Evagreen Supermix" (BIORAD). Primer sequences used for qPCRs are included in supplementary Table 2. Expression levels of genes were determined using the Real-Time PCR Detection SystemCFX384 (BIO-RAD). All mRNA expression levels were calculated relative to housekeeping genes, $\beta 2 \mathrm{M}$ or EF2, and were normalized using the ddCt method. Relative gene expression was calculated using the $2(-\mathrm{ddCt})$ method, where
ddCT was calculated by subtracting the average WT dCT from $\mathrm{dCT}$ of individual samples.

\section{Immunofluorescence analysis}

For immunofluorescence staining, frozen sections of adrenal glands were stained with an Anti-Tyrosine Hydroxylase antibody (ab76442) from Abcam. For additional visualization of the nuclei, cells were covered with DAPI. Fluorescent images were acquired on an ApoTome II Colibri (Carl Zeiss, Jena, Germany). Images were analyzed using Fiji (ImageJ distribution $1.52 \mathrm{~K}$ ) to quantify staining per region of interest (ROI).

\section{Cell culture}

Mouse pheochromocytoma cells (MPC - 4/30/PRR) were obtained from Arthur Tischler (Department of Pathology and Laboratory Medicine, Tufts University School of Medicine, Boston, MA, USA; and Dr. Pacak, NIH, Bethesda, MD) [35]. The MPC cells were plated on collagen A-coated flasks (Biochrom AG, Berlin, Germany) and maintained in RPMI 1640 medium containing 5\% fetal calf serum and 10\% horse serum (all from Life Technologies, Darmstadt, Germany) at $37{ }^{\circ} \mathrm{C}, 95 \%$ humidity, and $5 \% \mathrm{CO}_{2}$.

\section{Intracellular calcium uptake}

MPCs were cultured in 24-well plates in low serum medium - Opti-MEM (Thermo Fisher Scientific). Cells were plated onto collagen-coated plates in Opti-MEM for $3 \mathrm{~h}$ and subjected to respective treatment conditions of either glucose (D-(+)-glucose) (Sigma Aldrich) or erythropoietin (Roche). Cells were harvested $24 \mathrm{~h}$ later, washed, transferred to a 96-well plate, and subjected to staining with $0.5 \mu \mathrm{mol}$ Fluo8-AM (Abcam) for $60 \mathrm{~min}$ at $37^{\circ} \mathrm{C}$ in assay buffer (HBSS with Pluronic F127 plus), followed by washing with HBSS and analysis on a BD FACS Canto.

\section{Statistical analyses}

All data are presented as mean \pm SEM. Data (WT control versus transgenic line) were analyzed using the Mann-Whitney $U$-test, or the unpaired $t$-test with Welch's correction, as appropriate (after testing for normality with the $F$ test). All statistical analyses were performed on GraphPad Prism ver. 7.02 for Windows (GraphPad Software, La Jolla, CA, USA, www.graphpad.com). Significance was set at $p<0.05$; " $n$ " in figure legends denotes individual samples. 


\section{Results}

\section{Alterations in hypoxia pathway proteins reduce adrenal epinephrine}

Previously, we described a mouse line with conditional PHD2 and HIF1 $\alpha$ inactivation in a variety of cells (CD68:cre-PHD2/HIF1 $\alpha^{\mathrm{ff} / \mathrm{ff}}$-henceforth designated $\mathrm{P} 2 \mathrm{H} 1$ ), including neurons and renal EPO-producing cells (REPC), which results in local HIF $2 \alpha$ stabilization that leads to excessive systemic EPO and erythrocytosis (Supplementary Fig. 1A) [25]. As these cell lineages are thought to derive from neural crest cells [28, 36, 37], we looked at the effects of modulating hypoxia pathway proteins in another neural crest-derived cell type, namely, chromaffin cells, which are located in the medulla of the adrenal gland. First, to confirm genetic targeting of both hypoxia pathway proteins, we performed genomic PCRs on laser microdissected adrenal medullary tissue confirming

A
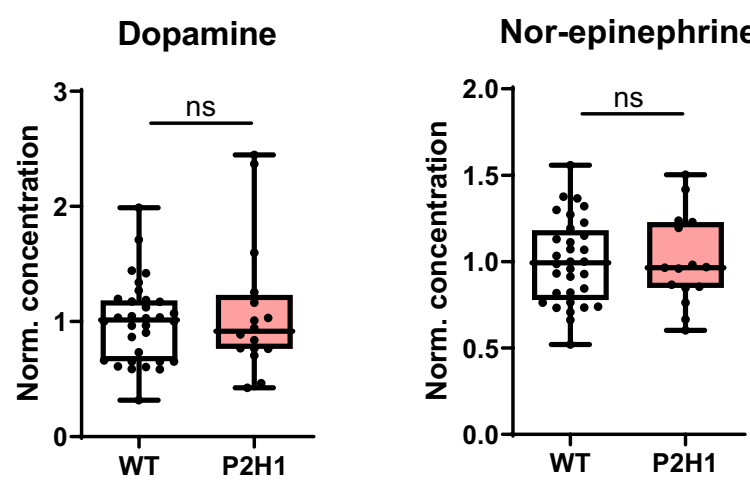

C localized targeting of PHD2 and HIF1 $\alpha$ (Supplementary Fig. 1B). Furthermore, qPCR analysis using mRNA from whole adrenal glands showed reduction of $P h d 2$ and Hifl $\alpha$ compared to the WT littermate controls, and an associated increase in Hif $2 \alpha$ (Supplementary Fig. 1C). Next, catecholamine levels in adrenal gland lysates showed a dramatic decrease in only epinephrine in $\mathrm{P} 2 \mathrm{H} 1$ mice compared to their WT littermates, but not of the upstream hormones, namely, dopamine and norepinephrine (Fig. 1A). We also observed a corresponding marked decrease in Pnmt mRNA, protein, and enzymatic activity (Fig. 1B-D). Conversely, no differences in the expression of other catecholamine-associated enzymes, such as $T h$ or $D b h$, were detected (Supplementary Fig. 1D). In addition, we found no difference in the amount of TH-protein using immunofluorescence staining (Supplementary Fig. 1E). Taken together, these results show that inhibition of the oxygen sensor PHD2 and one of its downstream HIF targets in the adrenal gland leads to diminished epinephrine synthesis.

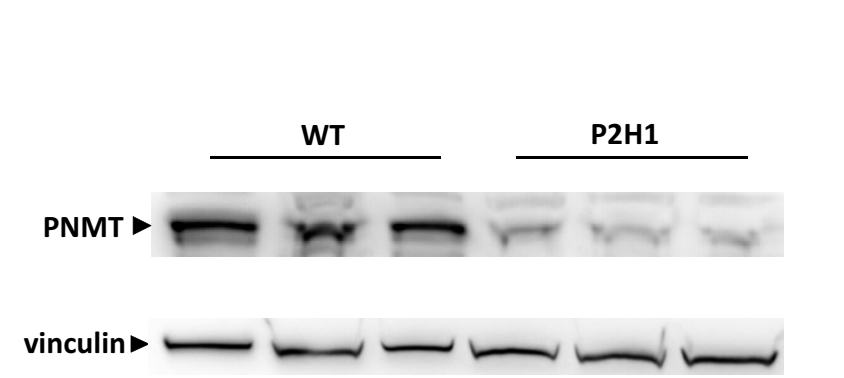

vinculin

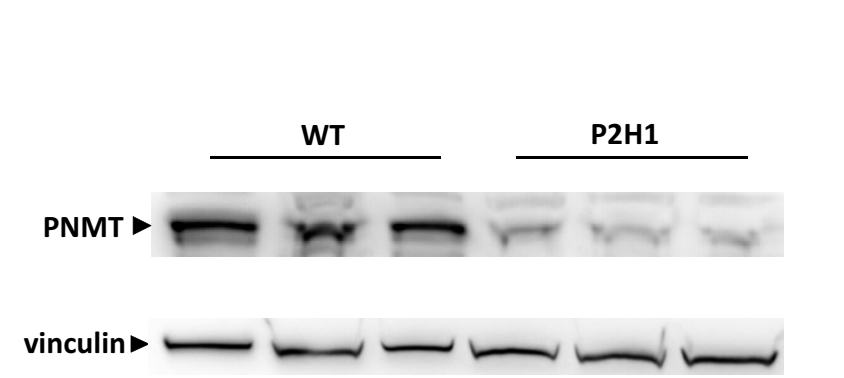

Fig. 1 Loss of PHD2 and HIF1 results in decreased epinephrine synthesis and PNMT activity in the adrenal gland. A Box and whisker plots showing catecholamine measurements in the adrenals from WT mice in comparison to littermate $\mathrm{P} 2 \mathrm{H} 1$ mice $(n=16-31$ individual adrenal glands). All data is normalized to average measurements in WT mice. The graphs are a representative result of at least 3 independent experiments. B qPCR-based mRNA expression analysis of

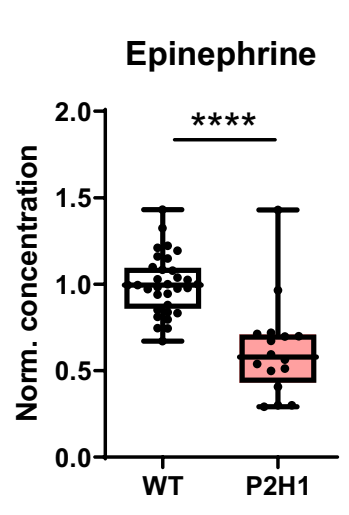

B
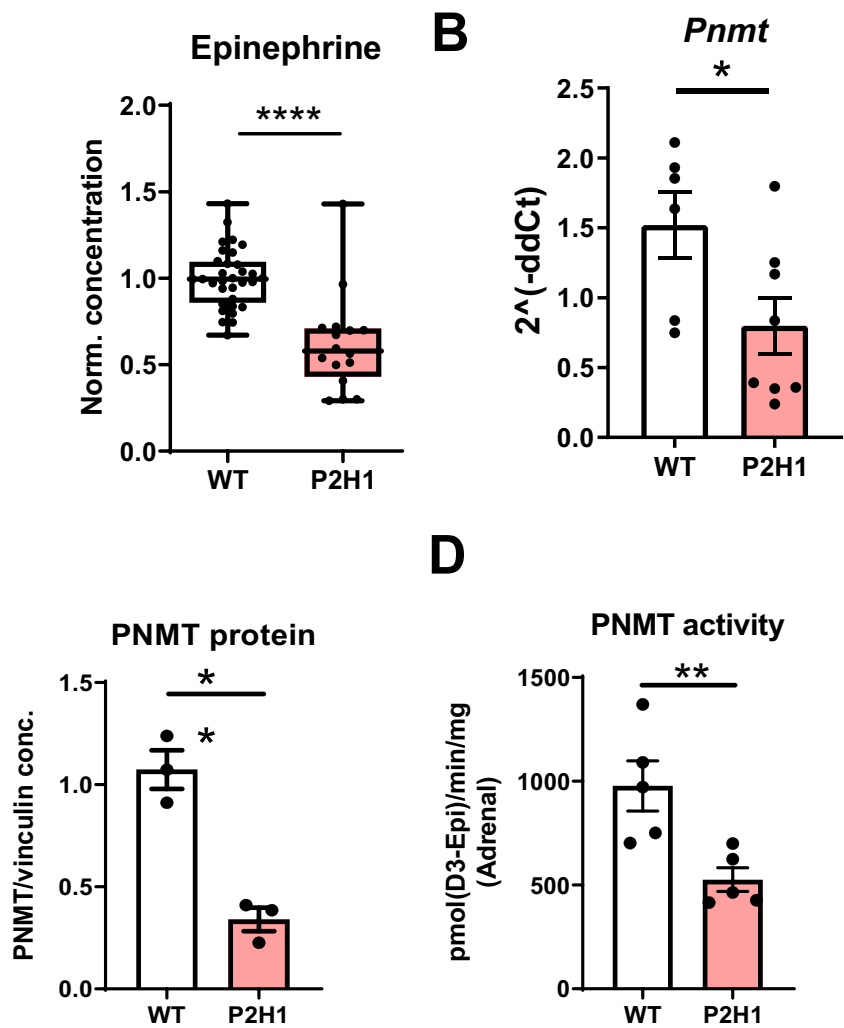

Pnmt in the adrenal gland from individual P2H1 mice and WT littermates ( $n=6-8$ individual adrenals). C Western blot analysis and comparison of PNMT protein from the adrenals of P2H1 mice and WT controls ( $n=6$ vs 3 individual adrenals). D PNMT enzyme activity in the adrenals of P2H1 mice compared to the WT littermate controls. Statistical significance was defined using the Mann-Whitney $U$-test $(* p<0.05 ; * * p<0.005)$ 


\section{Decreased adrenal epinephrine synthesis is unrelated to loss of HIF1a}

To verify the impact of the individual hypoxia pathway proteins, we took advantage of the CD68:cre-PHD2 $2^{\mathrm{f} / \mathrm{f}}$ mouse line (henceforth designated P2) [2, 25] and a newly created CD68:cre-HIF $1 \alpha^{\mathrm{f} / \mathrm{f}}$ line (henceforth designated H1). Similar to our findings in $\mathrm{P} 2 \mathrm{H} 1$ mice, $\mathrm{P} 2$ mice exhibited significantly lower levels of epinephrine in the adrenal glands compared to their WT littermates (Fig. 2A), along with reduced Pnmt mRNA and PNMT enzyme activity (Fig. 2B). Th and $D b h$ levels remained unaffected in P2 mice (Supplementary Fig. 2). However, compared to WT mice, H1 mice showed no differences in any of hormones measured (Fig. 2C), strongly suggesting that loss of HIF $1 \alpha$ alone does not play a significant role in catecholamine production in the adrenal gland. Importantly, these results support our initial observation that PHD2 alters epinephrine synthesis, probably due to HIF2 $\alpha$ stabilization.

\section{Increased EPO is associated with PNMT-independent reduction in adrenal epinephrine synthesis}

We have previously shown that both $\mathrm{P} 2$ and $\mathrm{P} 2 \mathrm{H} 1$ mice, but not H1 mice, exhibit EPO-induced erythrocytosis [25] (Supplementary Fig. 1A); we therefore investigated the potential relationships between reduced epinephrine levels in the adrenal glands and EPO-associated changes. Therefore, we tested the EPO transgenic mouse line (EPO Tg6) [38], which are known to constitutively express high levels of EPO leading to increased RBCs without influencing adrenal hypoxia pathway proteins (Supplementary Fig. 3A-B). Interestingly, similar to P2 and P2H1 mice, epinephrine along with dopamine levels was significantly lower in the adrenal glands of EPO Tg6 mice (Fig. 3A). In contrast to $\mathrm{P} 2 \mathrm{H} 1$ and $\mathrm{P} 2$ mice, however, no differences in PNMT activity were observed, despite increased Pnmt mRNA levels (Fig. 3B). Congruently, mRNA analysis on whole adrenals revealed no changes in $T h$ or $D b h$ (Supplementary Fig. 3B). Taken together, these observations suggest that PNMT-independent reduction in adrenal epinephrine levels correlated to high systemic EPO.
A

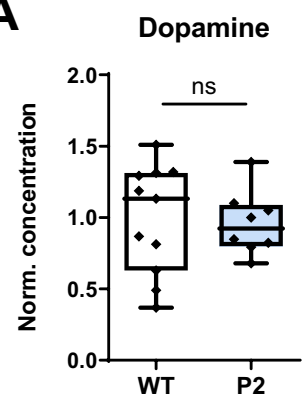

Nor-epinephrine
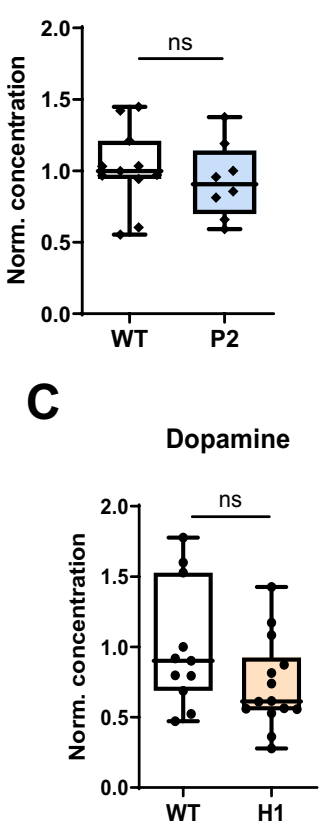

Epinephrine

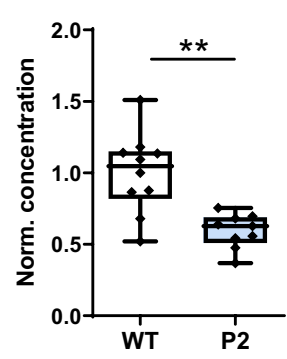

Nor-epinephrine

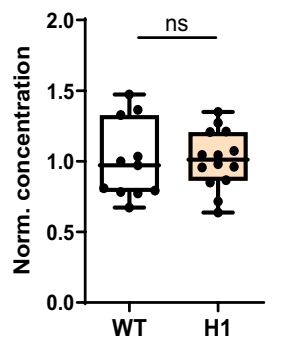

B
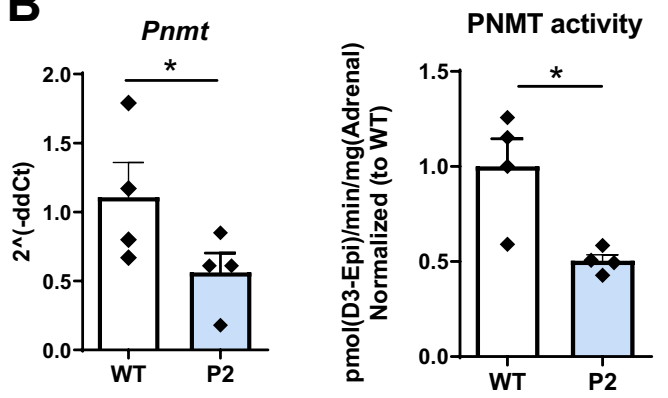

Fig. 2 Decreased epinephrine and PNMT in the adrenal are related to the loss of PHD2 but unrelated to HIF1. A Box and whisker plots comparing catecholamine measurements in the adrenals from P2 mice and WT littermates ( $n=8-11$ individual adrenal glands). All data are normalized to average measurements in WT mice. The graphs are a representative result of at least 3 independent experiments. B qPCR-based mRNA expression analysis of Pnmt and PNMT activity in the adrenals of the individual mice ( $n=4$ vs 4$)$. C Catecholamine measurements in the adrenals of HIF1 mice compared to WT controls ( $n=11-14$ individual adrenal glands). All data are normalized to the average of measurements in WT mice. Statistical significance was defined using the Mann-Whitney $U$-test $\left({ }^{*} p<0.05\right.$; $* * p<0.005)$ 
Fig. 3 Lower epinephrine in the adrenals of EPO Tg6 mice. A Box and whisker plots comparing catecholamine measurements in the adrenals from EPO Tg6 mice and WT littermates ( $n=19$ vs 18 individual adrenal glands). All data are normalized to average measurements in WT mice. The graphs are a representative result of at least 3 independent experiments. B PNMT enzyme activity and qPCR-based mRNA expression analysis of Pnmt in the adrenals of individual mice ( $n=8$ vs 10$)$. All data are normalized to the average of measurements in WT mice. Statistical significance was defined using the MannWhitney $U$-test $(* p<0.05$; $* * p<0.005)$

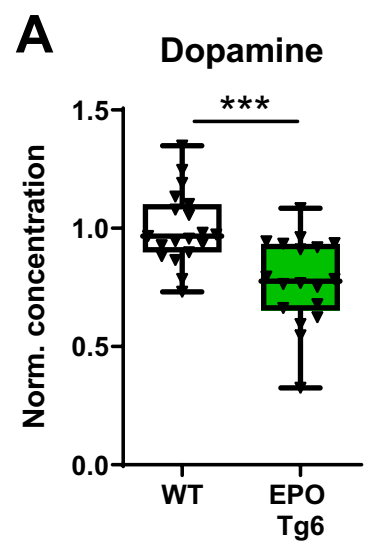

Nor-epinephrine

Epinephrine
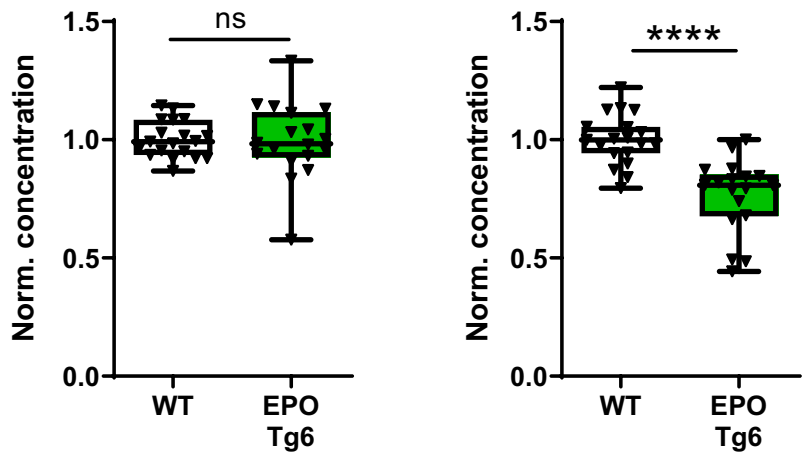

B
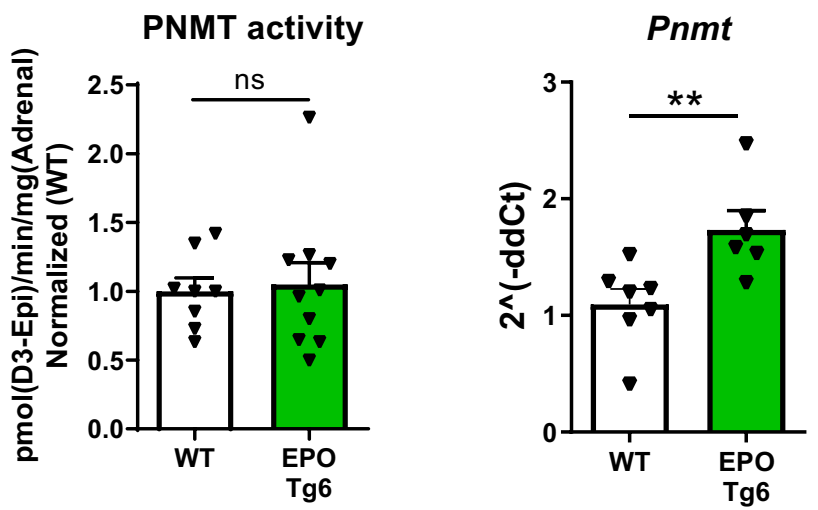

\section{EPO/erythropoiesis regulates epinephrine release from the adrenal gland}

To characterize the impact of systemic EPO/erythropoiesis on epinephrine in adrenal glands, we looked at potential changes in secretion by measuring epinephrine in urine and found a marked increase in urinary epinephrine in EPO $\operatorname{Tg} 6$ mice (Fig. 4A), suggesting either direct or indirect effect of EPO on epinephrine release from the adrenal gland. Similarly, and despite PNMT-dependent inhibition of epinephrine in the adrenal gland (Fig. 1A-B), P2H1 mice showed an almost significant increase in urine epinephrine compared to WT littermates (Fig. 4B).

To further investigate these findings, we used a previously described anemic mouse strain, namely, FOXD1:creHIF2 $\alpha^{\mathrm{f} / \mathrm{f}}[28]$. These mice show low systemic EPO levels and a dramatic reduction in circulatory RBCs (Supplementary Fig. 4A) [28]. In direct contradiction to urinary data of the erythrocytotic EPO Tg6 mice, FOXD1:cre-HIF2 $\alpha^{\mathrm{f} / \mathrm{f}}$ mice showed a $>$ eightfold reduction in urinary epinephrine compared to WT littermates (Fig. 4C). Interestingly, the adrenal glands of these anemic mice showed a significant increase in dopamine, while levels of all other catecholamines remained unchanged (Fig. 4D). Levels of neither PNMT (Fig. 4E) nor of any of the other corresponding enzymes were altered (Supplementary Fig. 4B). Taken together, at this point, our data strongly point towards EPO-mediated exocytosis of epinephrine and which is independent of the PHD2/HIF2/ PNMT axis regulating the synthesis of epinephrine in the chromaffin cells.

\section{EPO-induced hypoglycemia activates epinephrine release}

Epinephrine release from chromaffin cells requires their exocytosis and this process is stimulated by hypoglycemia while inhibited by hyperglycemia [17, 20]. Recently, it has been shown that hyperactive erythropoiesis, as seen in EPO Tg6 mice, increases systemic glucose consumption and consequent hypoglycemia, which is most probably attributable to a greater number of circulating RBCs [22]. Therefore, we sought to understand if and how EPO-associated hypoglycemia can affect adrenal epinephrine release. We first measured blood glucose levels (BGLs) in all mouse lines and found that both erythrocytotic $\mathrm{P} 2 \mathrm{H} 1$ and EPO Tg6 mice display significant hypoglycemia (Fig. 5A), while conversely, the anemic FOXD1:cre-HIF $2 \alpha^{\mathrm{f} / \mathrm{f}}$ mice were dramatically hyperglycemic (Fig. 5B). Next, we used a mouse pheochromocytoma cell line (MPC) to study how changes in blood glucose levels could affect cellular exocytosis. As these cells do not produce measurable amounts of epinephrine, we measured the uptake of calcium upon glucose stimulation, directly correlating with the degree 
A

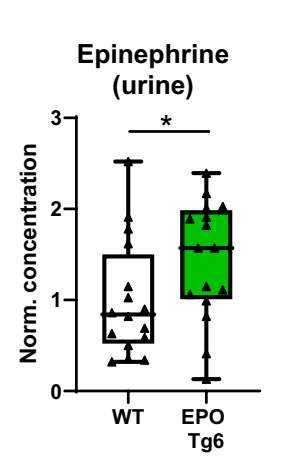

B

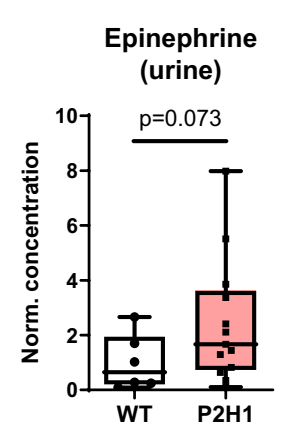

C

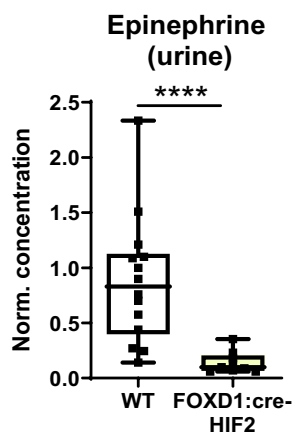

D

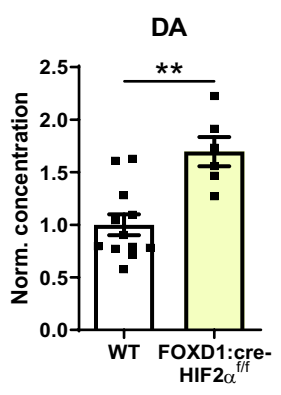

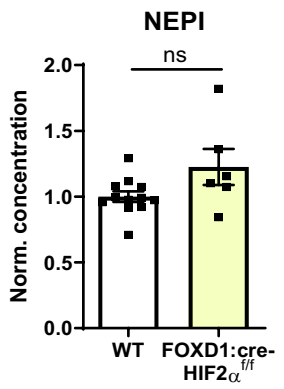

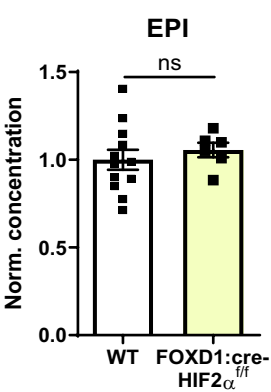

E
Fig. 4 Modulated urinary epinephrine in erythrocytotic and anemic mice. A Box and whisker plots comparing urinary epinephrine in EPO Tg6 mice and WT littermates ( $n=16$ vs 16 mice). B Box and whisker plots comparing urinary epinephrine in $\mathrm{P} 2 \mathrm{H} 1$ mice and WT littermates ( $n=6$ vs 13 mice). C Box and whisker plots comparing urinary epinephrine in FOXD1:cre-HIF $2 \alpha^{\mathrm{f} / \mathrm{f}}$ mice and WT littermates ( $n=14$ vs 9 mice). All urine measurements were normalized to urinary creatinine and data was further normalized to average measurements in WT mice. The graphs are a representative result of at least 3 independent experiments. D Catecholamine measurements in the

of epinephrine exocytosis [39, 40]. Therefore, we exposed MPCs to increasing concentrations of glucose and observed a significant inhibition of calcium uptake, indicating reduced exocytosis (Fig. 5C). In contrast, direct exposure of MPCs to high EPO did not lead to changes in intracellular calcium (Supplementary Fig. 5A and B), clearly suggesting that EPO would not directly influence epinephrine exocytosis; rather, it is systemic hypoglycemia secondary to EPO-induced erythrocytosis in mice that enhances adrenal epinephrine release. Conversely, anemia induces hyperglycemia resulting in the inhibition of epinephrine release.

\section{Discussion}

Here, we show that decreased PNMT expression in the PHD2-deficient adrenal medulla reduces epinephrine synthesis, but systemic effects in these PHD2-deficient mice, such as enhanced EPO production, consequent RBC excess, and hypoglycemia, lead to enhanced secretion of this hormone from the adrenal gland (Fig. 6). These results indicate uncoupling between synthesis and secretion of epinephrine adrenals from FOXD1:cre-HIF2 $\alpha^{\mathrm{f} / \mathrm{f}}$ mice compared to WT littermates ( $n=12$ vs 6 individual adrenal glands). Data were further normalized to the average measurements in WT mice. The graphs are a representative result of at least 2 independent experiments. E PNMT enzymatic activity and qPCR-based mRNA expression analysis of Pnmt measurements in the adrenal of individual mice ( $n=8$ vs 10$)$. All data are normalized to average measurements in WT mice. Statistical significance was defined using the Mann-Whitney $U$-test $\left({ }^{*} p<0.05\right.$; $* * p<0.005)$

upon PHD2 loss leading to reduced size of adrenal epinephrine stores. Mechanistically, we show that excessive epinephrine secretion is related to EPO-induced systemic hypoglycemia, rather than a direct cell-level effect of EPO per se.

Multiple hypoxia pathway components have been suggested to define the functionality of the adrenal medulla. In the physiological sympathoadrenal setting, pVHL has been shown to be essential during development and it is required by the peripheral oxygen-sensing system to ensure survival under hypoxic conditions [41]. Loss-of-function mutations in the VHL gene or gain-of-function mutations in HIF $2 \alpha$ have been associated with the development of pheochromocytoma and paraganglioma [42]. Previously, it was suggested that HIF $2 \alpha$ is essential for catecholamine homeostasis during embryonic development [43]. However, this HIF subunit is not essential for the development and functionality of the adrenal medulla, as mice deficient for HIF $2 \alpha$ in TH-positive medullary cells display no functional abnormalities [44]. In contrast, a novel mouse line containing a HIF $2 \alpha$ gain-of-function mutation has been reported to 
A

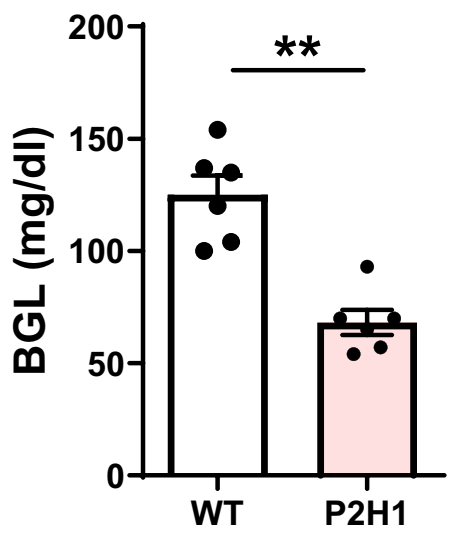

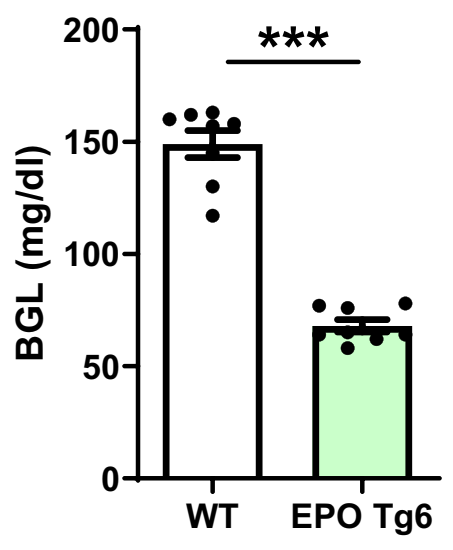

B

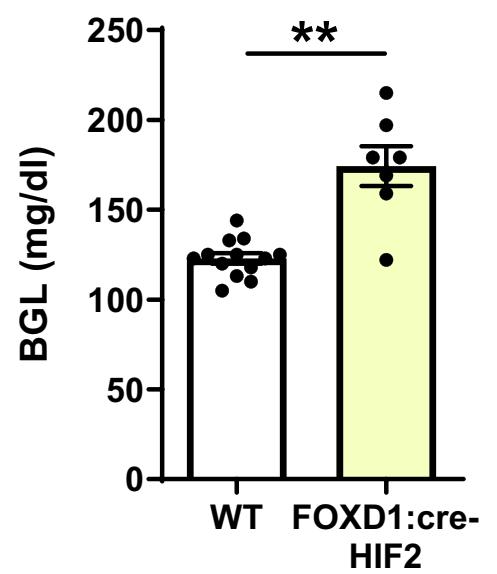

C

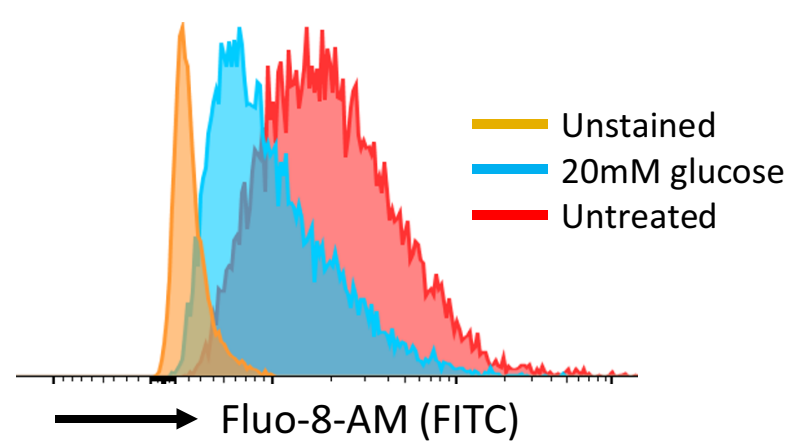

Intracellular calcium

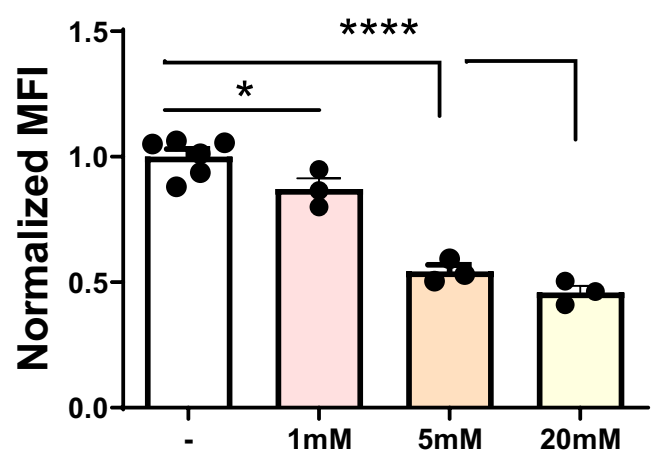

Fig. 5 EPO-mediated regulation of blood glucose levels in erythrocytotic and anemic mice. A Blood glucose level (BGL) measurements in P2H1 and EPO Tg6 mice compared to WT littermates $(n=6-8$ mice). B BGL in FOXD1:cre-HIF2 $\alpha^{\mathrm{f} / \mathrm{f}}$ mice compared to WT littermates ( $n=6-13$ mice). C Representative histograms showing fluorescence of the Fluo-8-Am dye for intracellular calcium measurement in untreated MPC cells compared to stimulation with glucose. Normalized MFI depicting intracellular calcium measurement in MPC cells that were treated with glucose in a dose-dependent manner. Each dot represents an individual well. The data is representative of 2 individual experiments. Statistical significance was defined using the MannWhitney $U$-test or unpaired $t$-test $(* p<0.05 ; * * p<0.005)$ display reduced adrenal PNMT and urinary metanephrine/ normethanephrine ratios, although no data on potential modulation of catecholamines in the adrenal gland were provided [14]. Our data on HIF2 $\alpha$-induced reduction in PNMT activity concur with these observations. Likewise, several in vitro studies have described the effects of HIF $2 \alpha$ on the various enzymes involved in the process of catecholamine production in chromaffin-related cell lines [7-9, 45, 46]. Our findings that HIF $2 \alpha$ induction in medullar cells results in the repression of Pnmt mRNA and its activity appear counterintuitive but might be the result of an indirect effect driven by transcriptional repressors. In line with this, transcriptional regulation of adrenal steroidogenesis has already been connected to miRNAs, some of which might be directly regulated by hypoxia/HIF $[47,48]$. Therefore, more research is required to elucidate the direct or indirect impact of HIF $2 \alpha$ on the production of epinephrine. The role of HIF1 $\alpha$ in the adrenal medulla remains much less explored, despite results suggesting indirect activation of the Pnmt promotor by HIF1 $\alpha$ via the transcription factors Egr-1 and Sp1 [49]. Therefore, further insight into how PHDs/HIFs regulate epinephrine production and release from the adrenal medulla in an in vivo setting is essential to further implement this knowledge in the promising field of HIF stabilizers (HIFPHD inhibitors) in the treatment of anemia. However, it must be noted here that concerns have been recently raised regarding the chronic use of such HIF stabilizers [3, 50-53].

The advantage of our approach lies in the use of multiple transgenic mice lines to define the individual roles of PHD2 and HIF1 $\alpha$ in epinephrine physiology, which was complimented by studies in mice that are conditionally deficient for both PHD2 and HIF $1 \alpha$ in cells of neural origin, i.e., REPCs $[25,54]$. Observations from all these mouse lines strongly suggest targeting of chromaffin cells in the adrenal medulla. We have previously reported HIF2 $\alpha$ stabilization in P2H1 mice and demonstrated that the excessive erythrocytosis 


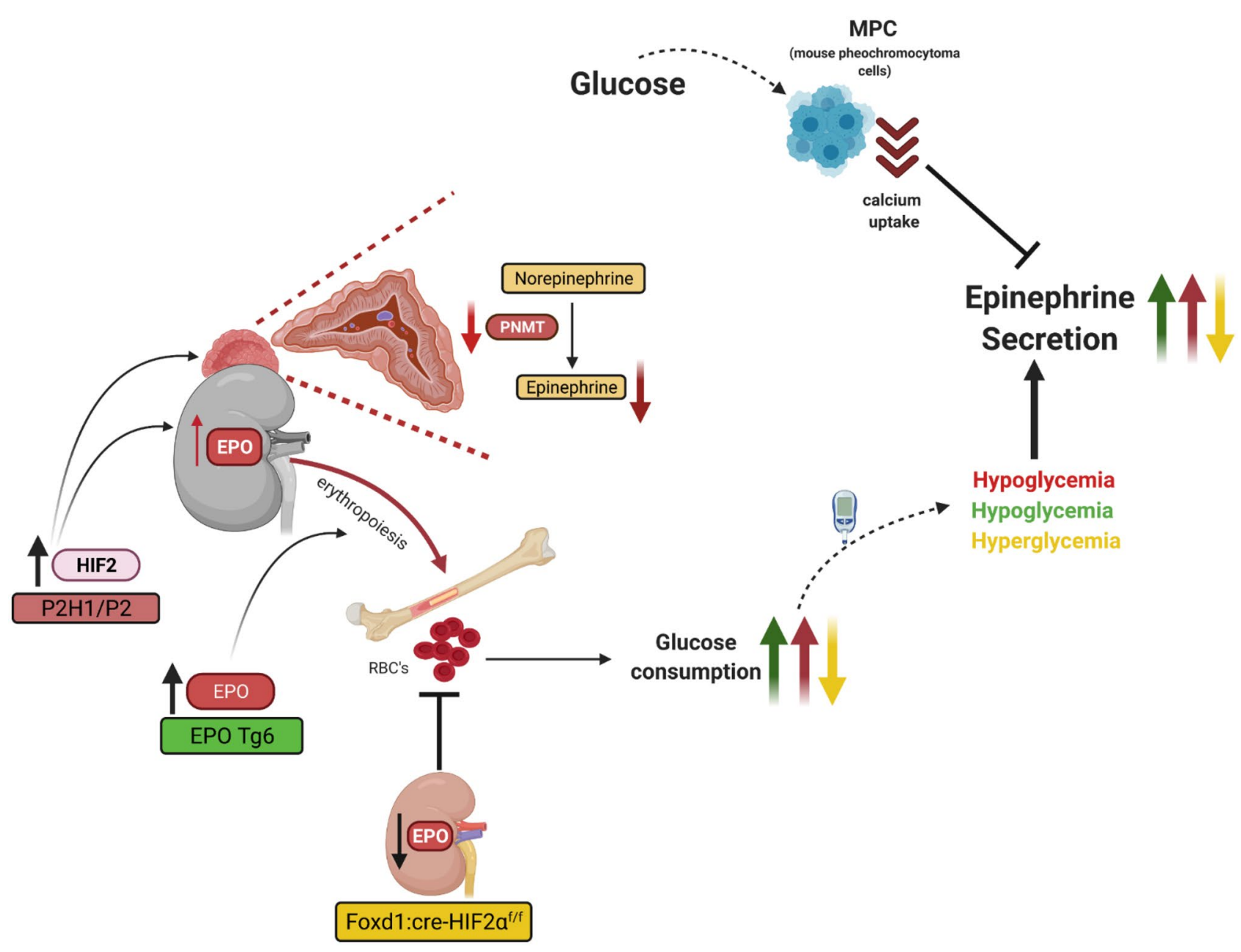

Fig. 6 Graphical overview of the PHD2-HIF2 $\alpha$ axis involved in synthesis and secretion of epinephrine from the mouse adrenal gland

phenotype seen in these $\mathrm{P} 2 \mathrm{H} 1$ mice is attributable to HIF2 $\alpha$ stabilization in the absence of the protective effects of HIF1 $\alpha$ [25]. Similarly, we show that loss of PHD2 alone, but not of HIF1 alone, resembled the $\mathrm{P} 2 \mathrm{H} 1$ phenotype with respect to changes in epinephrine synthesis and secretion, indicating that this phenotype too is enhanced through stabilization of HIF $2 \alpha$ and that HIF $1 \alpha$ might not have a significant role. Further, although we found a comparable decrease in epinephrine levels in $\mathrm{P} 2 \mathrm{H} 1$ and $\mathrm{P} 2$ adrenal glands and a corresponding reduction in adrenal PNMT activity, urinary excretion of epinephrine was higher in $\mathrm{P} 2 \mathrm{H} 1$ mice, suggesting that epinephrine was preferentially released from the adrenal glands. As P2H1 mice also display excessive erythrocytosis that is associated with very high levels of EPO, we hypothesized that this excessive EPO was responsible for the observed preferential release of epinephrine. Therefore, we used erythrocytotic EPO Tg6 mice to understand the effects of only the EPO/polycythemia phenotype on epinephrine physiology without interference from the HIF2PNMT pathway [38], and show that excessive EPO indeed increases urinary epinephrine excretion, thereby supporting our hypothesis.

Under basal conditions, exocytosis from the chromaffin cells is a strictly controlled process that largely depends on calcium uptake [55-58]. However, it can be further enhanced by additional stimuli, including hypoglycemia, hypotension, hypoxemia, and emotional distress $[5,16,58$, 59]. Interestingly, it has been recently reported that EPO Tg6 mice are strongly hypoglycemic and that low BGL correlates with the degree of erythropoiesis [22, 60]. Moreover, it was postulated almost a century ago that hypoglycemia can per se stimulate epinephrine release from the adrenal medulla [61]. The results of our in vitro experiments in MPCs lend support to this hypothesis as we show that calcium uptake reduces as glucose concentration increases, and that direct EPO exposure does not produce such an effect. Thus, based on our observations, we suggest, for the first time, that EPOinduced RBC excess, and consequent hypoglycemia, leads to enhanced exocytosis of epinephrine that is mediated by enhanced $\mathrm{Ca}^{2+}$ uptake in chromaffin cells. Further, higher 
Pnmt mRNA and reduced dopamine levels in EPO Tg6 adrenal glands are most likely the consequence of such enhanced exocytosis. These conclusions are borne out by the contrasting observations in the anemic FOXD1:cre-HIF $2 \alpha^{\mathrm{f} / \mathrm{f}}$ mice [28], which show dramatically low levels of epinephrine in urine that were linked to hyperglycemia, even though adrenal epinephrine and PNMT levels remained unchanged.

In summary, we show that PHD2-mediated HIF2 $\alpha$ stabilization in the offspring of neural crest cells has divergent local and systemic effects in vivo, i.e., while epinephrine synthesis is diminished, its urinary excretion is enhanced. Importantly, in these mice, the adrenal synthesis of epinephrine and its urinary secretion appear to be clearly uncoupled as excessive urinary epinephrine secretion appears to be due to systemic EPOinduced effects via the PHD2-HIF2-EPO axis, which include excessive erythrocytosis and consequent increase in glucose consumption by these RBCs. Mechanistically, we propose that the EPO-induced RBC excess and consequent hypoglycemia lead to enhanced exocytosis of epinephrine, irrespective of the primary reduction in adrenal epinephrine synthesis. These findings have potential clinical significance in view of broad spectrum HIF-PHD inhibitors currently under phase III trials.

Supplementary Information The online version contains supplementary material available at https://doi.org/10.1007/s00109-021-02121-y.

Acknowledgements We would like to thank Dr. Vasuprada Iyengar for English Language and content editing, and Dr. Max Gassmann for the EPO Tg6 mice.

Author contribution D.W. designed and performed majority of the experiments, analyzed data, and wrote the manuscript. N.B. performed experiments, analyzed data, and contributed to the discussion. A.Me. provided essential tools, performed experiments, and analyzed data. D.K., A.K., and J.S. performed experiments and analyzed data. A.E.A. and T.C. provided tools and contributed to the data discussion. G.E. and M.P. provided tools, analyzed data, and contributed to the data discussion. B.W. designed and supervised the overall study, analyzed data, and wrote the manuscript.

Funding Open Access funding enabled and organized by Projekt DEAL. This work was supported by grants from the DFG (German Research Foundation) within the CRC/Transregio 205/1, Project No. 314061271-TRR205, "The Adrenal: Central Relay in Health and Disease" (A02) to B.W., T.C., and A.E.A.; (B12) to N.B. and G.E; (S01) to D.K. and M.P.; B.W. was supported by the Heisenberg program, DFG, Germany; WI3291/5-1 and 12-1.

Availability of data and material All data and material are available upon reasonable request to ben.wielockx@tu-dresden.de.

Code availability Not applicable.

\section{Declarations}

Ethics approval All mice were bred and maintained in accordance with facility guidelines on animal welfare and with protocols approved by the Landesdirektion Sachsen, Germany.
Consent to participate Not applicable.

Consent for publication Not applicable.

Conflict of interest The authors declare no competing interests.

Open Access This article is licensed under a Creative Commons Attribution 4.0 International License, which permits use, sharing, adaptation, distribution and reproduction in any medium or format, as long as you give appropriate credit to the original author(s) and the source, provide a link to the Creative Commons licence, and indicate if changes were made. The images or other third party material in this article are included in the article's Creative Commons licence, unless indicated otherwise in a credit line to the material. If material is not included in the article's Creative Commons licence and your intended use is not permitted by statutory regulation or exceeds the permitted use, you will need to obtain permission directly from the copyright holder. To view a copy of this licence, visit http://creativecommons.org/licenses/by/4.0/.

\section{References}

1. Schodel J, Ratcliffe PJ (2019) Mechanisms of hypoxia signalling: new implications for nephrology. Nat Rev Nephrol 15:641-659. https://doi.org/10.1038/s41581-019-0182-z

2. Franke K, Gassmann M, Wielockx B (2013) Erythrocytosis: the HIF pathway in control. Blood 122:1122-1128. https://doi.org/ 10.1182/blood-2013-01-478065

3. Watts D, Gaete D, Rodriguez D, Hoogewijs D, Rauner M, Sormendi S, Wielockx B (2020) Hypoxia pathway proteins are master regulators of erythropoiesis. Int J Mol Sci. https://doi.org/10.3390/ijms21218131

4. Watts D, Stein J, Meneses A, Bechmann N, Neuwirth A, Kaden D, Kruger A, Sinha A, Alexaki VI, Luis Gustavo P-R et al (2021) HIF1alpha is a direct regulator of steroidogenesis in the adrenal gland. Cell Mol Life Sci 78:3577-3590. https://doi.org/10.1007/ s00018-020-03750-1

5. Berends AMA, Eisenhofer G, Fishbein L, Horst-Schrivers A, Kema IP, Links TP, Lenders JWM, Kerstens MN (2019) Intricacies of the molecular machinery of catecholamine biosynthesis and secretion by chromaffin cells of the normal adrenal medulla and in pheochromocytoma and paraganglioma. Cancers (Basel). https://doi.org/10.3390/cancers11081121

6. Tank AW, Lee Wong D (2015) Peripheral and central effects of circulating catecholamines. Compr Physiol 5:1-15. https://doi.org/ 10.1002/cphy.c140007

7. Brown ST, Kelly KF, Daniel JM, Nurse CA (2009) Hypoxia inducible factor (HIF)-2 alpha is required for the development of the catecholaminergic phenotype of sympathoadrenal cells. J Neurochem 110:622-630. https://doi.org/10.1111/j.1471-4159.2009. 06153.x

8. Bechmann N, Poser I, Seifert V, Greunke C, Ullrich M, Qin N, Walch A, Peitzsch M, Robledo M, Pacak K et al (2019) Impact of extrinsic and intrinsic hypoxia on catecholamine biosynthesis in absence or presence of Hif2alpha in pheochromocytoma cells. Cancers (Basel). https://doi.org/10.3390/cancers11050594

9. Qin N, de Cubas AA, Garcia-Martin R, Richter S, Peitzsch M, Menschikowski M, Lenders JW, Timmers HJ, Mannelli M, Opocher G et al (2014) Opposing effects of HIF1alpha and HIF2alpha on chromaffin cell phenotypic features and tumor cell proliferation: insights from MYC-associated factor X. Int J Cancer 135:2054-2064. https://doi.org/10.1002/ijc.28868

10. Huynh TT, Pacak K, Wong DL, Linehan WM, Goldstein DS, Elkahloun AG, Munson PJ, Eisenhofer G (2006) Transcriptional 
regulation of phenylethanolamine $\mathrm{N}$-methyltransferase in pheochromocytomas from patients with von Hippel-Lindau syndrome and multiple endocrine neoplasia type 2. Ann N Y Acad Sci 1073:241-252. https://doi.org/10.1196/annals.1353.026

11. Lee SE, Oh E, Lee B, Kim YJ, Oh DY, Jung K, Choi JS, Kim J, Kim SJ, Yang JW et al (2016) Phenylethanolamine N-methyltransferase downregulation is associated with malignant pheochromocytoma/ paraganglioma. Oncotarget 7:24141-24153. https://doi.org/10. 18632/oncotarget.8234

12. Vogel TW, Brouwers FM, Lubensky IA, Vortmeyer AO, Weil RJ, Walther MM, Oldfield EH, Linehan WM, Pacak K, Zhuang Z (2005) Differential expression of erythropoietin and its receptor in von hippel-lindau-associated and multiple endocrine neoplasia type 2-associated pheochromocytomas. J Clin Endocrinol Metab 90:3747-3751. https://doi.org/10.1210/jc.2004-1899

13. Amorim-Pires D, Peixoto J, Lima J (2016) Hypoxia pathway mutations in pheochromocytomas and paragangliomas. Cytogenet Genome Res 150:227-241. https://doi.org/10.1159/000457479

14. Wang H, Cui J, Yang C, Rosenblum JS, Zhang Q, Song Q, Pang Y, Fang F, Sun M, Dmitriev P et al (2019) A transgenic mouse model of Pacak(-)Zhuang syndrome with an Epas1 gain-of-function mutation. Cancers (Basel). https://doi.org/10.3390/cancers 11050667

15. Verberne AJ, Korim WS, Sabetghadam A, Llewellyn-Smith IJ (2016) Adrenaline: insights into its metabolic roles in hypoglycaemia and diabetes. Br J Pharmacol 173:1425-1437. https://doi. org/10.1111/bph.13458

16. Feuerstein G, Gutman Y (1971) Preferential secretion of adrenaline or noradrenaline by the cat adrenal in vivo in response to different stimuli. Br J Pharmacol 43:764-775. https://doi.org/10. 1111/j.1476-5381.1971.tb07212.x

17. Takiyyuddin MA, Cervenka JH, Sullivan PA, Pandian MR, Parmer RJ, Barbosa JA, O’Connor DT (1990) Is physiologic sympathoadrenal catecholamine release exocytotic in humans? Circulation 81:185-195. https://doi.org/10.1161/01.cir.81.1.185

18. Dubois M, Vacher P, Roger B, Huyghe D, Vandewalle B, KerrConte J, Pattou F, Moustaid-Moussa N, Lang J (2007) Glucotoxicity inhibits late steps of insulin exocytosis. Endocrinology 148:1605-1614. https://doi.org/10.1210/en.2006-1022

19. Somanath S, Barg S, Marshall C, Silwood CJ, Turner MD (2009) High extracellular glucose inhibits exocytosis through disruption of syntaxin 1A-containing lipid rafts. Biochem Biophys Res Commun 389:241-246. https://doi.org/10.1016/j.bbrc.2009.08.126

20. Reimann M, Qin N, Gruber M, Bornstein SR, Kirschbaum C, Ziemssen T, Eisenhofer G (2017) Adrenal medullary dysfunction as a feature of obesity. Int J Obes (Lond) 41:714-721. https://doi. org/10.1038/ijo.2017.36

21. Katz O, Stuible M, Golishevski N, Lifshitz L, Tremblay ML, Gassmann M, Mittelman M, Neumann D (2010) Erythropoietin treatment leads to reduced blood glucose levels and body mass: insights from murine models. J Endocrinol 205:87-95. https://doi. org/10.1677/JOE-09-0425

22. Rao TN, Hansen N, Hilfiker J, Rai S, Majewska JM, Lekovic D, Gezer D, Andina N, Galli S, Cassel T et al (2019) JAK2-mutant hematopoietic cells display metabolic alterations that can be targeted to treat myeloproliferative neoplasms. Blood 134:18321846. https://doi.org/10.1182/blood.2019000162

23. Dey S, Scullen T, Noguchi CT (2015) Erythropoietin negatively regulates pituitary ACTH secretion. Brain Res 1608:14-20. https://doi.org/10.1016/j.brainres.2015.02.052

24. Singh RP, Franke K, Kalucka J, Mamlouk S, Muschter A, Gembarska A, Grinenko T, Willam C, Naumann R, Anastassiadis K et al (2013) HIF prolyl hydroxylase 2 (PHD2) is a critical regulator of hematopoietic stem cell maintenance during steady-state and stress. Blood 121:5158-5166. https://doi.org/10.1182/blood-2012-12-471185

25. Franke K, Kalucka J, Mamlouk S, Singh RP, Muschter A, Weidemann A, Iyengar V, Jahn S, Wieczorek K, Geiger K et al (2013) HIF-1alpha is a protective factor in conditional PHD2-deficient mice suffering from severe HIF-2alpha-induced excessive erythropoiesis. Blood 121:1436-1445. https://doi.org/10.1182/blood-2012-08-449181

26. Ryan HE, Lo J, Johnson RS (1998) HIF-1 alpha is required for solid tumor formation and embryonic vascularization. EMBO J 17:3005-3015

27. Vogel J, Kiessling I, Heinicke K, Stallmach T, Ossent P, Vogel O, Aulmann M, Frietsch T, Schmid-Schonbein H, Kuschinsky W et al (2003) Transgenic mice overexpressing erythropoietin adapt to excessive erythrocytosis by regulating blood viscosity. Blood 102:2278-2284. https://doi.org/10.1182/blood-2003-01-0283

28. Kobayashi H, Liu Q, Binns TC, Urrutia AA, Davidoff O, Kapitsinou PP, Pfaff AS, Olauson H, Wernerson A, Fogo AB et al (2016) Distinct subpopulations of FOXD1 stroma-derived cells regulate renal erythropoietin. J Clin Invest 126:1926-1938. https://doi.org/10.1172/ JCI83551

29. Kobayashi A, Mugford JW, Krautzberger AM, Naiman N, Liao J, McMahon AP (2014) Identification of a multipotent self-renewing stromal progenitor population during mammalian kidney organogenesis. Stem cell reports 3:650-662. https://doi.org/10.1016/j. stemcr.2014.08.008

30. Gruber M, Hu CJ, Johnson RS, Brown EJ, Keith B, Simon MC (2007) Acute postnatal ablation of Hif-2alpha results in anemia. Proc Natl Acad Sci U S A 104:2301-2306. https://doi.org/10. 1073/pnas.0608382104

31. Bechmann N, Watts D, Steenblock C, Wallace PW, Schurmann A, Bornstein SR, Wielockx B, Eisenhofer G, Peitzsch M (2021) Adrenal hormone interactions and metabolism: a single sample multi-omics approach. Horm Metab Res 53:326-334. https://doi. org/10.1055/a-1440-0278

32. Eisenhofer G, Goldstein DS, Stull R, Keiser HR, Sunderland T, Murphy DL, Kopin IJ (1986) Simultaneous liquid-chromatographic determination of 3,4-dihydroxyphenylglycol, catecholamines, and 3,4-dihydroxyphenylalanine in plasma, and their responses to inhibition of monoamine oxidase. Clin Chem 32:2030-2033

33. Peitzsch M, Pelzel D, Glockner S, Prejbisz A, Fassnacht M, Beuschlein F, Januszewicz A, Siegert G, Eisenhofer G (2013) Simultaneous liquid chromatography tandem mass spectrometric determination of urinary free metanephrines and catecholamines, with comparisons of free and deconjugated metabolites. Clin Chim Acta 418:50-58. https://doi.org/10.1016/j.cca.2012.12.031

34. Qin N, Peitzsch M, Menschikowski M, Siegert G, Pacak K, Eisenhofer G (2013) Double stable isotope ultra performance liquid chromatographic-tandem mass spectrometric quantification of tissue content and activity of phenylethanolamine $\mathrm{N}$-methyltransferase, the crucial enzyme responsible for synthesis of epinephrine. Anal Bioanal Chem 405:1713-1719. https://doi.org/10.1007/s00216-012-6599-x

35. Powers JF, Evinger MJ, Tsokas P, Bedri S, Alroy J, Shahsavari M, Tischler AS (2000) Pheochromocytoma cell lines from heterozygous neurofibromatosis knockout mice. Cell Tissue Res 302:309-320. https://doi.org/10.1007/s004410000290

36. Asada N, Takase M, Nakamura J, Oguchi A, Asada M, Suzuki N, Yamamura K, Nagoshi N, Shibata S, Rao TN et al (2011) Dysfunction of fibroblasts of extrarenal origin underlies renal fibrosis and renal anemia in mice. J Clin Invest 121:3981-3990. https:// doi.org/10.1172/JCI57301

37. Lee G, Kim H, Elkabetz Y, Al Shamy G, Panagiotakos G, Barberi T, Tabar V, Studer L (2007) Isolation and directed differentiation of neural crest stem cells derived from human embryonic stem cells. Nat Biotechnol 25:1468-1475. https://doi.org/10.1038/nbt1365

38. Ruschitzka FT, Wenger RH, Stallmach T, Quaschning T, de Wit C, Wagner K, Labugger R, Kelm M, Noll G, Rulicke T et al (2000) Nitric oxide prevents cardiovascular disease and determines survival in polyglobulic mice overexpressing erythropoietin. Proc Natl Acad Sci U S A 97:11609-11613. https://doi.org/10.1073/ pnas.97.21.11609 
39. Douglas WW (1968) Stimulus-secretion coupling: the concept and clues from chromaffin and other cells. Br J Pharmacol 34:451474. https://doi.org/10.1111/j.1476-5381.1968.tb08474.x

40. Smith U, Smith DS, Winkler H, Ryan JW (1973) Exocytosis in the adrenal medulla demonstrated by freeze-etching. Science 179:79-82. https://doi.org/10.1126/science.179.4068.79

41. Macias D, Fernandez-Aguera MC, Bonilla-Henao V, LopezBarneo J (2014) Deletion of the von Hippel-Lindau gene causes sympathoadrenal cell death and impairs chemoreceptor-mediated adaptation to hypoxia. EMBO Mol Med 6:1577-1592. https://doi. org/10.15252/emmm.201404153

42. Scriba LD, Bornstein SR, Santambrogio A, Mueller G, Huebner A, Hauer J, Schedl A, Wielockx B, Eisenhofer G, Andoniadou CL et al (2020) Cancer stem cells in pheochromocytoma and paraganglioma. Front Endocrinol (Lausanne) 11:79. https://doi.org/ 10.3389/fendo.2020.00079

43. Tian H, Hammer RE, Matsumoto AM, Russell DW, McKnight SL (1998) The hypoxia-responsive transcription factor EPAS1 is essential for catecholamine homeostasis and protection against heart failure during embryonic development. Genes Dev 12:3320-3324

44. Macias D, Cowburn AS, Torres-Torrelo H, Ortega-Saenz P, Lopez-Barneo J, Johnson RS (2018) HIF-2alpha is essential for carotid body development and function. Elife. https://doi.org/10. 7554/eLife.34681

45. Schnell PO, Ignacak ML, Bauer AL, Striet JB, Paulding WR, Czyzyk-Krzeska MF (2003) Regulation of tyrosine hydroxylase promoter activity by the von Hippel-Lindau tumor suppressor protein and hypoxia-inducible transcription factors. J Neurochem 85:483-491. https://doi.org/10.1046/j.1471-4159.2003.01696.x

46. Richter S, Qin N, Pacak K, Eisenhofer G (2013) Role of hypoxia and HIF2alpha in development of the sympathoadrenal cell lineage and chromaffin cell tumors with distinct catecholamine phenotypic features. Adv Pharmacol 68:285-317. https://doi.org/10. 1016/B978-0-12-411512-5.00014-2

47. Azhar S, Dong D, Shen WJ, Hu Z, Kraemer FB (2020) The role of miRNAs in regulating adrenal and gonadal steroidogenesis. J Mol Endocrinol 64:R21-R43. https://doi.org/10.1530/JME-19-0105

48. Hu Z, Shen WJ, Kraemer FB, Azhar S (2017) Regulation of adrenal and ovarian steroidogenesis by miR-132. J Mol Endocrinol 59:269-283. https://doi.org/10.1530/JME-17-0011

49. Wong DL, Tai TC, Wong-Faull DC, Claycomb R, Siddall BJ, Bell RA, Kvetnansky R (2010) Stress and adrenergic function: HIF1alpha, a potential regulatory switch. Cell Mol Neurobiol 30:1451-1457. https://doi.org/10.1007/s10571-010-9567-z
50. Semenza GL (2019) Pharmacologic targeting of hypoxia-inducible factors. Annu Rev Pharmacol Toxicol 59:379-403. https://doi.org/ 10.1146/annurev-pharmtox-010818-021637

51. Kaplan J (2019) Roxadustat and anemia of chronic kidney disease. N Engl J Med 381:1070-1072. https://doi.org/10.1056/NEJMe1908978

52. Anker MS, Butler J, Anker SD (2020) Roxadustat for anemia in patients with chronic kidney disease. N Engl J Med 383:e3. https://doi.org/10.1056/NEJMc1913712

53. Sanghani NS, Haase VH (2019) Hypoxia-inducible factor activators in renal anemia: current clinical experience. Adv Chronic Kidney Dis 26:253-266. https://doi.org/10.1053/j.ackd.2019.04. 004

54. Lage TL, Miranda MF, Bittencourt Mde J, Dias CM, Parijos AM, Raiol TK (2013) Case for diagnosis. Granular cell tumor An Bras Dermatol 88:1005-1007. https://doi.org/10.1590/abd1806-4841. 20132772

55. Aunis D, Langley K (1999) Physiological aspects of exocytosis in chromaffin cells of the adrenal medulla. Acta Physiol Scand 167:89-97. https://doi.org/10.1046/j.1365-201x.1999.00580.x

56. Holz RW, Brondyk WH, Senter RA, Kuizon L, Macara IG (1994) Evidence for the involvement of Rab3a in $\mathrm{Ca} 2+$-dependent exocytosis from adrenal chromaffin cells. J Biol Chem 269:10229-10234

57. Garcia AG, Garcia-De-Diego AM, Gandia L, Borges R, GarciaSancho J (2006) Calcium signaling and exocytosis in adrenal chromaffin cells. Physiol Rev 86:1093-1131. https://doi.org/10.1152/ physrev.00039.2005

58. Marengo FD, Cardenas AM (2018) How does the stimulus define exocytosis in adrenal chromaffin cells? Pflugers Arch 470:155167. https://doi.org/10.1007/s00424-017-2052-5

59. Lenders JW, Eisenhofer G (2014) Pathophysiology and diagnosis of disorders of the adrenal medulla: focus on pheochromocytoma. Compr Physiol 4:691-713. https://doi.org/10.1002/cphy.c130034

60. Oburoglu L, Tardito S, Fritz V, de Barros SC, Merida P, Craveiro M, Mamede J, Cretenet G, Mongellaz C, An X et al (2014) Glucose and glutamine metabolism regulate human hematopoietic stem cell lineage specification. Cell Stem Cell 15:169-184. https://doi.org/10.1016/j.stem.2014.06.002

61. Cannon WB, McIver A, SW B, (1924) Studies on the conditions of activity in endocrine glands. XIII. A sympathetic and adrenal mechanism for mobilizing sugar in hypoglycemia. Am J Physiol 69:46-66

Publisher's Note Springer Nature remains neutral with regard to jurisdictional claims in published maps and institutional affiliations. 